\title{
Léxico caipira oral atual da área semântica 'religião e crenças' em Itu, cidade em intento de tornar-se Patrimônio Mundial
}

\section{“Caipira” Dialect's Current Oral Lexicon Related to Religion and Beliefs in Itu, a City Intending to Become a World Heritage}

\author{
Selmo Ribeiro Figueiredo Junior [selmo.figueiredo@ff.cuni.cz] \\ Univerzita Karlova, República Tcheca
}

\begin{abstract}
RESUMO
Aborda-se o nível lexical atual do vernáculo falado em uma das cidades historicamente mais importantes da região do Médio Tietê - berço do dialeto caipira do Estado de São Paulo, Brasil - chamada Itu. A área semântica é 'religião e crenças'. As formas investigadas são: 〈capeta〉, 〈diabo〉, 〈demônio〉, 〈úcifer〉, ‘(as)sombração), 〈espírito〉, ‘fantasma〉, ‘alma〉, ‘encosto〉, 〈macumba〉, ‘feitiço〉, ‘amuleto (da sorte)〉, ‘medalha/medalhinha〉 e rescapulário». No âmbito dos estudos performados por Romero (2007) e Figueiredo Jr. (2019), essas lexias foram produzidas por 24 informantes ituanos no total, entrevistados in loco mediante a aplicação de duas versões do questionário semântico-lexical do Projeto Atlas Linguístico do Brasil (Projeto ALiB). Do ponto de vista dialetológico, objetiva-se ineditamente analisar tais lexias e identificar seus estatutos atuais em função de correlações com variáveis extralinguísticas (diagenérica, diageracional, diastrática e diarreligiosa). Ademais, notas etimológicas são adicionalmente fornecidas.
\end{abstract}

\section{Palavras-chave}

Dialeto caipira; português paulista; análise dialetológica; Médio Tietê; São Paulo

\begin{abstract}
This study deals with the current spoken lexicon of Itu, one of the most historically important Brazilian cities within Médio Tietê, a region that belongs to São Paulo State and is the cradle of "Caipira" dialect in the mentioned State. The semantic area concerned is related to religion and beliefs, and the specific forms are: 〈capeta〉, 〈diabo〉, 〈demônio〉, 〈úcifer〉, ‘(as)sombração〉, 〈espírito〉, 〈fantasma〉, ‘alma〉, 〈encosto〉, 〈macumba〉, 〈feitiço〉, ‘amuleto (da sorte)〉, ‘medalha/medalhinha〉, and «escapulário〉. Romero (2007) and Figueiredo Jr. (2019) directly collected these data from 24 informants in the form of an interview based on two versions of a questionnaire by the Linguistic Atlas of Brazil ("ALiB") Project. As an original aim of this paper, the aforementioned denoting items are dialectologically analyzed, and their current status is identified in correlation with extralinguistic variables (diagender-specific, diagenerational, diastratic, and diarreligious). Further, etymological information is also provided.
\end{abstract}

\section{KEYWORDS}

"Caipira" dialect; São Paulo State Portuguese; dialectological analysis; Médio Tietê region; São Paulo State

RECEBIDO 2021-04-30; ACEITE 2021-05-26 


\section{Introdução}

Precipuamente, este artigo reporta dois estudos dialetológicos sobre o léxico atual do vernáculo oral de Itu (localidade do Estado de São Paulo, Brasil) da área semântica 'religião e crenças' (Romero 2007 e Figueiredo 2019), por um lado, e, por outro, como seu objetivo, traz análises inéditas a respeito.

Os dados lexicais levantados por Romero (2007) são uma produção de 16 informantes, divididos entre jovens e idosos, rurais e urbanos, via entrevistas onomasiológicas diretas, in loco. Com um aporte teórico-metodológico diversificado (sobretudo da dialetologia e da sociolinguística), seu objetivo era verificar se certas lexias, registradas por Amaral (1920) - precursor dos estudos do dialeto caipira -, ainda se faziam presentes e, por consequência, flagrar processos de desaparecimento, manutenção, variação ou mudança.

Por seu turno, a investigação de Figueiredo Jr. (2019) cobriu dez das localidades mais representativas e antigas da região do Médio Tietê, berço da cultura caipira paulista e um dos primeiros centros difusores da lusitanização do Brasil, incluindo Itu ${ }^{1}$, que atualmente planeja tornar-se Patrimônio Mundial junto à Organização das Nações Unidas para a Educação, a Ciência e a Cultura (UNESCO), por conta de sua privilegiada configuração linguística, histórica, cultural e também natural, ou seja, patrimonial imaterial/intangível e material/tangível. Com aporte teórico-metodológico especificamente da Dialetologia Pluridimensional (Radtke e Thun 1996; Thun 2000, 2005), a elicitação de dados como um todo deu-se via entrevistas onomasiológicas a 80 informantes no total (oito ituanos) in loco.

A próxima seção, 2, contempla uma contextualização extralinguística de Itu preliminar à abordagem dialetológica presente na seção seguinte, 3. A contextualização refere-se a informações atinentes à origem, ao desenvolvimento e ao estado corrente da localidade. Quanto à abordagem dialetológica, lexias da área semântica 'religião e crenças' são relatadas e ineditamente analisadas em correlação com variáveis extralinguísticas, nomeadamente com a diagenérica, com a diageracional, com a diastrática e com a diarreligiosa. Como complementares, breves notas etimológicas são apresentadas. O artigo se encerra com conclusões extraídas das seções precedentes e com considerações finais acerca do interesse do município em tornar-se Patrimônio Mundial.

\section{Itu: contextualização extralinguística preliminar}

Em sua origem uma fazenda de lavoura com alguns índios conhecida antes pelo nome tupi ‘y-tuguaçu ('grande salto d'água') ${ }^{2}$ do bandeirante ${ }^{3}$ Domingos Fernandes, Itu (de 〈y-tu〉) foi fundada

1 As demais cidades são: Santana de Parnaíba, Pirapora do Bom Jesus, Araçariguama, São Roque, Sorocaba, Porto Feliz, Tietê, Capivari e Piracicaba.

2 Aplicam-se aqui a grafia e a semântica adotadas por Carvalho (1987) a propósito de 〈y-tu〉 ('salto d'água', 'cachoeira' ou 'cascata'; op. cit. 312) e de 〈-guaçu〉 (sufixo com valor semântico adjetivo morfologicamente formador de substantivo, significando 'grande' ou 'roliço'; op. cit. 92).

3 Comum entre 1550 e 1720 no Brasil, um bandeirante era um expedicionário participante de alguma bandeira, nome dado a uma expedição armada que costumava partir da então capitania de São Vicente (atual São Paulo) rumo aos sertões do interior. Por seu turno, capitania (hereditária) era o nome dado a cada uma das unidades político-administrativas do Brasil Colônia no século XVI. Para história e geografia das bandeiras, v. p. ex. Coppes Jr. (2021). 
por este e por seu genro, Cristóvão Diniz, ao edificarem uma capela à Nossa Senhora da Candelária em 1610 (onde hoje é o Largo do Bom Jesus, também conhecido por Praça Padre Anchieta). Mais tarde, a localidade passou às respectivas categorias de: distrito/freguesia da antiga Vila de Parnaíba (atual município de Santana de Parnaíba) em 1653; vila em 1657; e cidade em 1842 (Ferreira 1957). Com o nome administrativo "Estância Turística de Itu” a partir de 2015, sua população foi estimada para 2020 em mais de 175 mil (IBGE 2021).

A localidade de Itu - como primeiro porto aurífero do interior do continente da América do Sul no século XVII (Marins 2016 apud Castilho 2017: 2); firmada como entreposto comercial entre a região sul do país e as minas de ouro de Mato Grosso e Goiás em meados do século XVIII; e como importante produtora de algodão e açúcar em 1776 (Ximenes 2018: 154) - tornou-se a vila mais rica da Província de São Paulo em 1777, chegando a exportar açúcar à Europa, commodity substituída pelo café no século XIX.

[...] Itu sempre desempenhou papel saliente, tornando-se um dos mais brilhantes centros intelectuais da antiga província. Levada pelo desejo de independência pátria e pelos anseios de liberdade, Itu se ergue resoluta contra a Bernarda de Francisco Inácio, escrevendo então as mais gloriosas páginas de sua história e recebendo do Príncipe Regente o honroso título de Fidelíssima por seus esforços pela nossa independência e pelo espírito de brasilidade; centro do liberalismo paulista nas vésperas e primórdios da nossa independência, assim a ela se referiu um ilustre historiador: pelo sincero espírito religioso de seu povo, pelo clero numeroso, virtuoso e ilustrado, por suas numerosas e magníficas igrejas e pelo esplendor de suas festas, um distinto prelado lhe dá o título de Roma Brasileira. Em 1871 é fundado o Clube Republicano e Itu é escolhido para a Magna Convenção do Partido Republicano, a qual se realiza a 18 de abril de 1873, advindo-lhe daí o título de Meca Republicana (Ferreira 1957: 484). ${ }^{4}$

No tocante à composição étnica da cidade, Francischinelli (2019), em evento acadêmico recente, reportou que inventários de 1780 a 1830 encontrados no Arquivo Histórico do Museu Republicano "Convenção de Itu" registram grande diversidade de etnias presentes na história de Itu, citando "benguela, congo, cassange, guiné, mina, angola, entre outras” (p. 9). Em meados do século XX, houve um boom demográfico na localidade em função de ondas de imigração rural atraídas por empregos no setor econômico secundário (notadamente na indústria de cerâmicas) e no setor terciário (Ximenes 2018).

Pelo último censo demográfico, 2010, de um total de 154.147 residentes em Itu: 109.640 declararam-se de cor/raça branca; 6.990, preta; 837, amarela; 36.562, parda; 92, indígena; e 26 nada declararam (SIDRA 2021). Ou seja, os não declarados e os autodeclarados amarelos e indígenas perfazem, cada, menos de $1 \%$ da população. A maioria se autodeclarou branca, $71 \%$, e o segundo maior grupo se autodeclarou pardo, 24\%. Quanto aos autodeclarados pretos, eles representam 5\%. Nesse mesmo censo, 126.097 indivíduos foram instados quanto à sua religião (ou crença): (1) 73\% da população declararam-se católicos; (2) 16\%, evangélicos; (3) 6\%, com outra religião/crença; e (4) $5 \%$ sem religião (ou crença). ${ }^{5}$

4 O nome de Prudente de Moraes, comemorado como o primeiro presidente civil do Brasil (1894-1898), encontra-se na ata dessa histórica convenção de Itu (Martins 2012: 91).

5 Em desdobramento respectivo: (1) 99,9\% apostólica romana, 0,06\% apostólica brasileira e 0,04\% ortodoxa; (2) 90,35\% de origem pentecostal e 9,65\% de missão; e (3) os seguintes grupos, com menos de $2 \%$ cada - considerando toda a população 
Do ponto de vista turístico, a cidade insere-se em dois importantes circuitos regionais: o Caminho do Sol e o Roteiro dos Bandeirantes. O primeiro abrange mais doze cidades ${ }^{6}$. Ximenes (2018: 105) endossa que esse caminho é considerado uma preparação para o Caminho de Santiago de Compostela, Espanha. Já o Roteiro dos Bandeirantes, pela chamada Estrada dos Romeiros (da qual a antiga Estrada de Itu faz parte), é seguido por peregrinos até hoje, que rumam para a cidade de Pirapora de Bom Jesus ${ }^{7}$. Por sua vez, o Roteiro dos Bandeirantes integra o Circuito Turístico da Hidrovia Tietê-Paraná, de importância nacional.

Quanto à salvaguarda e à conservação de bens culturais e naturais ituanos, a cidade conta com mais de vinte museus e memoriais, bem como com centros e espaços de memória. As instituições mais importantes são: Museu Republicano "Convenção de Itu” (cujo edifício-sede, base do Partido Republicano Paulista, está tombado junto ao Instituto do Patrimônio Histórico e Artístico Nacional, IPHAN); Espaço Cultural Almeida Júnior, que engloba o Museu de Arquivo Histórico Municipal de Itu (com coleções de Synésio Sampaio Góes) e o Museu de Música Sacra e Arte Religiosa Padre Jesuíno do Monte Carmelo (com acervo de imagens e outros objetos religiosos); e Museu da Energia (com acervo da história da energia).

Até 2019, junto ao já mencionado IPHAN - o qual segue convenções da Organização das Nações Unidas para a Educação, a Ciência e a Cultura (UNESCO) —, há (1) quatro bens tombados e (2) três em instrução (IPHAN 2021): (1.1) Igreja Matriz de Nossa Senhora da Candelária; (1.2) Igreja e Convento de Nossa Senhora do Carmo; (1.3) edifício-sede do Museu Republicano "Convenção de Itu”; (1.4) painéis de autoria do Padre Jesuíno do Monte Carmelo (expostos no edifício conventual das Irmãs de São José junto à Igreja de Nossa Senhora do Patrocínio); (2.1) Casa da Fazenda Conceição; (2.2) Companhia Ituana de Força e Luz (da São Paulo Ligth atualmente); e (2.3) Fábrica de Tecidos São Luiz.

Quanto à perspectiva hidrográfica, Itu está situada na sub-bacia Sorocaba/Médio Tietê (SP 2016) e conta com o rio Tietê (antigo Anhemby) como um dos principais fatores naturais responsáveis por seu surgimento e por seu desenvolvimento. Por esse rio, entre os séculos XVIII e XIX, tomou lugar boa parte das famosas monções, expedições fluviais feitas por autoridades administrativas, militares e particulares entre a capitania de São Paulo - passando ou partindo de Itu - e a capitania de Mato Grosso, em função sobretudo das minas de ouro desta última, frequentemente à custa de trabalho escravo (cf. Holanda 2000).

De 1991 a 2013, o poder executivo e o poder legislativo de Itu cooperaram na criação de seis Áreas de Proteção Ambiental (APAs): (1) APA Itu-Represa do Braiaiá; (2) APA Itu-Fazenda Vassoural; (3) APA Itu-Bairro Botuxim; (4) APA Itu-Cidade Nova I; (5) APA Itu-rio Tietê; e (6) APA Pedregulho (PETI 2021). O objetivo é proteger, entre outros elementos, floresta de Mata Atlântica, formações geológicas próprias e vegetação única. No âmbito da APA Itu-rio Tietê, a Estrada Parque, parte da Estrada dos Romeiros, é um bom exemplo do ecoturismo.

ituana: espírita, espiritualista, judaica, não determinada, indígena, esotérica, afro-brasileira; bem como cada um dos seguintes grupos, constituídos por indivíduos que ou não declararam, ou declararam: ser ateus, ser agnósticos, ser de outra religião cristã, não saber ou estar ligados às Testemunhas de Jeová ou à Igreja de Jesus Cristo dos Santos dos Últimos Dias (cf. SIDRA 2021).

6 O trajeto do Caminho do Sol é: Santana de Parnaíba (início), Pirapora do Bom Jesus, Cabreúva, Itu, Salto, Indaiatuba, Elias Fausto, Capivari, Mombuca, Saltinho, Piracicaba, Águas de São Pedro e São Pedro (fim).

7 Este é o trajeto do Roteiro dos Bandeirantes: Santana de Parnaíba (início), Pirapora do Bom Jesus, Araçariguama, Cabreúva, Itu, Salto, Porto Feliz e Tietê (fim). 
Considerando o valor patrimonial natural, histórico e artístico de tais bens - incluindo-se aí o Centro Histórico em si - da cidade, Toscano e Toscano (1977 apud Castilho 2017) consideramna uma "cidade-museu", o que segue explicitamente endossado mais recentemente pelo museólogo Castilho (2017).

\section{Léxico caipira oral atual da área semântica 'religião e crenças' em Itu}

O vernáculo oral ituano foi relativamente pouco investigado. Mencionem-se: Romero (2007), com um estudo semântico-lexical; Garcia (2015), com uma abordagem entoacional; e Figueiredo Jr. (2019), com uma pesquisa semântico-lexical e fonético-fonológica ${ }^{8}$. Esta seção enfoca os aspectos lexicais desses estudos para, como seu objetivo, apresentar uma análise dialetológica inédita complementada com informações etimológicas.

Romero (2007), assimetricamente, entrevistou seis jovens (25-45 anos) e dez idosos (50-90) de ambos os sexos, do campo e da cidade, naturais de Itu ou aí com residência por um terço da vida pelo menos ${ }^{9}$, a fim de verificar se certas lexias (nomeadamente substantivos, adjetivos e verbos, classes presumivelmente mais sujeitas à variação) do dialeto caipira paulista relatadas por Amaral (1920) - precursor como estudioso dessa variedade linguística - ainda se faziam presentes.

A pesquisadora aplicou o questionário semântico-lexical do II Workshop de Preparação dos Inquiridores para o Atlas Linguístico do Brasil - ALiB (Romero 2007: 62), com 210 questões distribuídas por 15 áreas semânticas: (1) acidentes geográficos, (2) fenômenos atmosféricos, (3) astros e tempo, (4) flora, (5) atividades domésticas e agropastoris, (6) fauna, (7) corpo humano, (8) cultura e convívio, (9) ciclos da vida, (10) religião e crenças, (11) festas, divertimentos e jogos infantis, (12) habitação, (13) alimentação e cozinha, (14) vestuário e (15) vida urbana. No particular da área (10), mais pertinente ao presente artigo, as questões levantadas no inquérito de campo figuram no Quadro 1.

\begin{tabular}{|c|l|}
\hline Questão & \multicolumn{1}{c|}{ Enunciado } \\
\hline 38 & $\begin{array}{l}\text { Como se chama [sic] aquelas orações escritas em um papel dobrado muitas vezes que se pen- } \\
\text { dura no pescoço, benzido? }\end{array}$ \\
\hline 39 & $\begin{array}{l}\text { Que nome se dá ao mesmo papel dobrado, mas que vale como um encantamento? É como um } \\
\text { feitiço? }\end{array}$ \\
\hline 40 & Como se chamava [sic] as queimas de fogos das festas da igreja, da cidade? \\
\hline
\end{tabular}

Quadro 1: Questões da área semântica 'religião e crenças' (Romero 2007: 72-3)

8 As investigações (1) de Garcia (2015) e (2) de Figueiredo Jr. (2019) envolveram outras localidades além de Itu: (1) Santana de Parnaíba, Pirapora do Bom Jesus, Porto Feliz, Tietê, Capivari, Itu e Piracicaba (região do Médio Tietê) e Braga, Bragança e Vila Real (norte de Portugal); (2) Santana de Parnaíba, Pirapora do Bom Jesus, Araçariguama, São Roque, Sorocaba, Porto Feliz, Tietê, Capivari e Piracicaba (Médio Tietê).

9 Para detalhes da metodologia, v. cap. 2 de Romero (2007). 
Os enunciados do Quadro 1 equivalem às definições que Amaral (1920) registrou para as lexias (1) 〈bentinho〉/〈patuá〉 (como resposta à Q38), (2) 〈caborje ${ }^{10}(\mathrm{Q} 39)$ e (3) 〈bataria〉 $(\mathrm{Q} 40)$, respectivamente.

Por um lado, a elicitação de Romero (2007: 112) diatopicamente (no sentido rural vs. urbano) e diageracionalmente documentou o reconhecimento de: (1.1) «bentinho〉 por quatro idosos rurais (IRs), por cinco idosos urbanos (IUs), por dois jovens rurais (JRs) e por nenhum jovem urbano (JU); (1.2) 〈patuá〉 por dois IRs, por três IUs, por três JRs e por dois JUs; (2) «caborje〉 por nenhum IR, por um IU, por nenhum JR e por nenhum JU; (3) bataria〉 por dois IRs, por dois IUs, por um JR e por nenhum JU. Por outro lado, sem o número absoluto de ocorrências desta vez e apenas com a correlação diageracional, ela adicionalmente registrou o uso de: (1) 〈relíquia〉 como covariante tanto de 〈bentinho〉 quanto de 〈patuá〉 entre idosos e jovens bem como «santinho〉 como covariante também tanto de 〈bentinho〉 quanto de 〈patuá〉, mas só entre jovens; (2) 〈macumba〉 entre idosos e jovens, 〈bruxaria〉 entre jovens bem como 〈patuá〉 e «simpatia〉 entre idosos como covariantes de «caborje〉; (3) 〈foguetório〉 e 〈roqueira〉 entre idosos e jovens, ‘quermesse〉 entre jovens e, apenas entre idosos, 〈queima de fogos〉, 〈rojão〉, 〈bomba〉, ‘queima de rojão〉 como covariantes de 〈bataria〉.

Ou seja, 〈bentinho〉 é uma lexia que, com sua denotação exposta de modo interrogativo no Quadro 1 (Q38), está em processo de desaparecimento, já que se faz presente apenas em 35\% dos jovens contra $90 \%$ dos idosos. Contrariamente, «patuá ganha força, porque presente em 83,3\% dos jovens contra $50 \%$ dos idosos. Quanto à lexia 〈caborje〉, ela está em processo de desaparecimento: jovens não a reconheceram, e só 10\% dos idosos o fizeram. Embora mais lentamente, ‘bataria〉 envereda pelo mesmo caminho: reconhecimento de $16 \%$ dos jovens contra $40 \%$ dos idosos (cf. Romero 2007: 138-140).

Figueiredo Jr. (2019), por seu turno, modificou e aplicou uma versão de 2001 do questionário semântico-lexical do Comitê Nacional do Projeto ALiB (CNPA 2001) com 170 questões distribuídas por 14 áreas semânticas: (1) acidentes geográficos, (2) fenômenos atmosféricos, (3) astros e tempo, (4) atividades agropastoris, (5) fauna, (6) corpo humano, (7) ciclos da vida, (8) convívio e comportamento social, (9) religião e crenças, (10) jogos e diversões infantis, (11) habitação, (12) alimentação e cozinha, (13) vestuário e acessórios e (14) vida urbana. As questões subsumidas à área (9), conectadas com o propósito mais específico deste artigo, que foram aplicadas na pesquisa figuram no Quadro 2.

\begin{tabular}{|c|l|}
\hline Questão & \multicolumn{1}{c|}{ Enunciado } \\
\hline 147 & Se Deus está no céu, quem está no inferno? \\
\hline 148 & $\begin{array}{l}\text { O que algumas pessoas dizem já ter visto à noite em cemitérios ou em casas, que se diz que é } \\
\text { do outro mundo? }\end{array}$ \\
\hline 149 & $\begin{array}{l}\text { Como se chama aquilo que, deixado numa encruzilhada, certas pessoas fazem para prejudicar } \\
\text { alguém? }\end{array}$ \\
\hline 150 & Que nome se dá aos objetos que algumas pessoas usam para dar sorte ou afastar males? \\
\hline 153 & $\begin{array}{l}\text { Como se chama a chapinha de metal com um desenho de santo que as pessoas usam, geral- } \\
\text { mente no pescoço, presa numa corrente? [...] }\end{array}$ \\
\hline
\end{tabular}

Quadro 2: Questões da área semântica 'religião e crenças' (Figueiredo Jr. 2019: 2.003-2.004) 
Oito informantes foram ouvidos, quatro mulheres e quatro homens, com moradia em Itu por três quartos da vida pelo menos, sendo os últimos cinco anos necessariamente de residência ininterrupta aí. Todos também foram equitativamente divididos: em duas faixas etárias, uma de jovens (18-36 anos) e outra de velhos ( $\geq 55$ ); e em dois grupos escolares, um com estudos até o ensino médio incompleto e outro com estudos superiores iniciados ou já concluídos. Portanto, as variáveis extralinguísticas sistemática e simetricamente controladas foram a diagenérica, a diageracional e a diastrática escolar. O Quadro 3 traz essas e outras informações dos informantes, coletadas in loco em 2017.

\begin{tabular}{|c|c|c|c|c|c|}
\hline Código & $\mathrm{F} / \mathrm{M}$ & $\mathrm{J} / \mathrm{V}$, idade & Nível diastrático & AEA & Prática religiosa \\
\hline Inf. 41 & $M$ & $\mathrm{~J}, 21$ & baixo & italiana e espanhola & nenhuma \\
\hline Inf. 42 & $\mathrm{~F}$ & $\mathrm{~J}, 24$ & alto & brasileira & evangélica \\
\hline Inf. 43 & F & $\mathrm{V}, 70$ & alto & italiana & católica \\
\hline Inf. 44 & $\mathrm{M}$ & $\mathrm{V}, 75$ & baixo & brasileira & católica \\
\hline Inf. 45 & $F$ & $\mathrm{~V}, 89$ & baixo & brasileira & católica \\
\hline Inf. 46 & $\mathrm{~F}$ & J, 19 & baixo & brasileira & evangélica \\
\hline Inf. 47 & $M$ & $\mathrm{~J}, 18$ & alta & italiana e indígena & católica \\
\hline Inf. 48 & $\mathrm{M}$ & $\mathrm{V}, 64$ & alta & portuguesa & católica \\
\hline
\end{tabular}

Quadro 3: Informações extralinguísticas (Figueiredo Jr. 2019: 1.905 e 1.916)

Para a elicitação lexical, foi aplicada a 'técnica de entrevista orientada à contundência responsiva/anuente' (TE) (Figueiredo Jr. 2019), que absorve a 'técnica de três tempos' (Thun 2000). Esta última, sumariamente caracterizada, constitui-se da implementação em sequência do passo de perguntar (para obtenção de respostas espontâneas), do passo de insistir (para obtenção de covariantes espontâneas) e do passo de sugerir (para registro do conhecimento passivo do informante acerca de lexias que lhe são apresentadas pelo inquiridor).

A TE, por seu turno, não se realiza necessariamente em sequência, porque seu objetivo central é obter a contundência do informante em qualquer estágio, inclusive já no primeiro passo, e então retroativamente estabelecer a ordem de relevância das lexias, o que é feito ora com base em informações já presentes no contexto, ora via perguntas de controle do pesquisador ao informante. ${ }^{11}$

No Quadro 4, encontra-se a 'cabeça de relevância' de cada indivíduo, isto é, a lexia inicial da

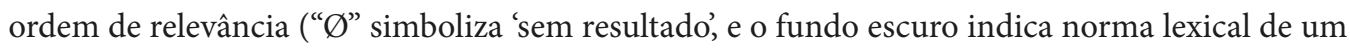
ponto de vista geral, i.e., sem correlações com as variáveis extralinguísticas).

11 Mais recentemente, a TT foi revisada e originou uma sucessora, denominada 'técnica de efeito tríplice', de funcionamento algorítmico (cf. Figueiredo Jr.; Margotti; Santiago-Almeida; Nascimento 2021). 


\begin{tabular}{|c|c|c|c|c|c|}
\hline Inf. & Q147 & Q148 & Q149 & Q150 & Q153 \\
\hline 41 & 〈lúcifer〉 & $\langle$ fantasma〉 & $\langle$ macumba $\rangle$ & 〈amuleto〉 & $\langle$ medalha〉 \\
\hline 42 & $\langle$ diabo〉 & $\langle$ fantasma $\rangle$ & $\langle$ macumba $\rangle$ & 〈amuleto da sorte〉 & $\varnothing$ \\
\hline 43 & $\varnothing$ & 〈alma de outro mundo〉 & macumba & $\varnothing$ & $\langle$ medalhinha〉 \\
\hline 44 & «capeta〉 & 〈assombração〉 & $\varnothing$ & $\varnothing$ & $\langle$ medalhinha〉 \\
\hline 45 & $\varnothing$ & 〈sombração〉 & $\langle$ feitiço〉 & 〈amuleto〉 & $\varnothing$ \\
\hline 46 & 〈capeta〉 & 〈espírito〉 & $\langle\mathrm{macumba}\rangle$ & ‘amuleto〉 & 〈escapulário〉 \\
\hline 47 & 〈demônio〉 & 〈assombração〉 & $\langle$ macumba $\rangle$ & 〈amuleto〉 & 〈escapulário〉 \\
\hline 48 & $\langle$ diabo〉 & $\varnothing$ & 〈cruzes e velas〉 & ‘amuleto〉 & $\langle$ medalhinha〉 \\
\hline
\end{tabular}

Quadro 4: Cabeças lexicais de relevância dos informantes de Itu (Figueiredo Jr. 2019: 1.905)

Ainda de um ponto de vista geral, 〈diabo〉 e 〈capeta〉 para Q147 dividem a posição de maior frequência relativa entre os resultados válidos, com 33\% cada, o que as torna lexias simetricamente rivais. Para Q148, «(as)sombração〉é a lexia mais frequente, com 43\%. Para Q149, «macumba〉, por possuir frequência superior a 50\%, é norma lexical, com $71 \%$ mais precisamente. Para Q150, ‘amuleto (da sorte)> é a única resposta, logo com 100\%, sendo também normal lexical. Para Q153, ‘medalha/medalhinha〉 também é norma lexical, com $66 \%$.

Saindo-se de uma observação geral rumo a visualizações específicas dos dados, distintas correlações entre as lexias e as variáveis extralinguísticas podem ser realizadas com diferentes extensões. A seguir, algumas possíveis.

De um ponto de vista diagenérico feminino, não há coincidência de uma única variante quanto a Q147, Q148 e Q153, do que se infere variação simétrica generalizada entre as mulheres. Em relação a Q149 e Q150, as duas normas apontadas pela perspectiva geral - «macumba〉 e «amuleto (da sorte)〉, respectivamente - são normas lexicais pela presente perspectiva também.

Pelo prisma diagenérico masculino, as respostas são todas incongruentes para Q147, do que se depreende variação simétrica generalizada. Para Q148 e Q149, respectivamente «assombração〉 e 〈macumba〉 são lexias prevalentes ${ }^{12}$ entre suas covariantes, com 66\% cada. Para Q150, há hegemonia absoluta de «amuleto〉, o que a faz norma lexical. Para Q153, «medalha/medalhinha〉 tem 66\% de frequência relativa com base nos resultados válidos, sendo assim norma lexical.

O ângulo diagenérico com ambos os grupos faz ver que «(as)sombração` para Q148 é, na amostra, apenas albergado pelos indivíduos masculinos.

Abordando-se os dados sob um ângulo diageracional, «capeta` para Q147 é uma lexia estável, por estar em manutenção sob uma consideração pela qual se faz uma projeção da constatação segundo a qual essa lexia tem uma mesma frequência entre jovens e velhos - no eixo diacrônico presumido no eixo sincrônico atual. Isso se aplica a ‘diabo〉 também. Ambas essas lexias, consideradas como covariantes, encontram-se em variação entre si competindo por hegemonia. Para Q148, ‘fantasma`é uma lexia progressiva, porque, além de ser uma forma prevalente entre os jo-

12 O termo lexia prevalente é, em geral, melhor aplicado quando a forma quantitativamente sobrepuja suas concorrentes sem, no entanto, ser uma norma. Porém, faz-se uso dele aqui também quando se trata de uma norma com uma sustentação quantitativa demasiadamente frágil. 
vens, ela não está entre os velhos da amostra dialetal em questão. Inversamente, ainda para Q148, ‘(as)sombração〉 é uma lexia regressiva, mais presente entre os velhos do que entre os jovens. Para Q149, «macumba〉é uma lexia progressiva dominante, presente entre todos os jovens instados e albergado só por um dos indivíduos velhos. Para Q150, ‘amuleto (da sorte)> reina absoluto, em forte manutenção, fazendo-a uma lexia estável. Para Q153, «medalha/medalhinha〉é uma lexia regressiva, frequente entre os velhos e com apenas uma instanciação entre os jovens. Para essa mesma questão, 〈escapulário〉 figura como lexia progressiva, presente em metade dos jovens e ausente entre os velhos.

Em uma ótica diastrática escolar, a lexia «capeta〉 para Q147 aparece só na classe baixa; e «diabo〉, só na classe alta; portanto, são lexias classistas na amostra. Para Q148, «(as)sombração» é uma lexia classista predominante na classe baixa, e (fantasma〉 é uma lexia imparcial. Para Q149, «macumba〉 é usado por ambas as classes. Para Q150, «amuleto (da sorte)〉 reina absoluto em ambas as classes, sendo assim uma lexia imparcial. Para Q153, «medalha/medalhinha` também é uma lexia imparcial.

As variáveis diagenérica, diageracional e diastrática escolar foram sistematicamente controladas. Contudo, informações diarreligiosas assistemáticas também foram registradas. O parágrafo a seguir traça uma correlação entre elas e os dados lexicais.

Para Q147, «diabo〉 e «capeta〉, as mais frequentes, são produtos de católicos e evangélicos indistintamente. Para Q148, «(as)sombração〉é uma lexia católica. Para Q149, «macumba〉 aparece como lexia de católicos e evangélicos indistintamente. Para Q150, ‘amuleto (da sorte)> está associado a católicos e evangélicos, sem diferença significativa. Para Q153, «medalha/medalhinha〉é uma lexia católica.

No parágrafo subsequente, coloca-se a ordem de relevância por completo referente às questões respondidas por cada informante, fornecendo o estatuto epistêmico de cada lexia: forma espontânea positiva (FP), forma sugerida aceita (FA) e forma stgerida rejeitada ${ }^{13}$ (FR), sendo o algarismo arábico, quando existente, uma indicação cronológica entre lexias com o mesmo estatuto.

Inf. 41: 〈úcifer〉 FP1, 〈diabo〉 FP2 e «capeta〉FA (Q147); 〈fantasma〉 FA1, 〈assombração〉 FA2 e 〈espírito〉 FA3 (Q148); 〈macumba〉 FP, ‘feitiço〉 FA e «tespacho〉 FR (Q149); ‘amuleto〉FP (Q150); e «medalha FA (Q153). Inf. 42: «diabo〉 FP (Q147); ‘fantasma〉 FP (Q148); «macumba〉 FP (Q149); «amuleto da sorte FP (Q150); $\varnothing ~(Q 153)$. Inf. 43: $\varnothing$ (Q147); ‘alma de outro mundo〉 FP (Q148); 〈macumba〉 FP (Q149); ‘amuletø FR (Q150); e «medalhinha〉 FP2 e «escapulário〉 FP1 (Q153). Inf. 44: 〈capeta〉 FP (Q147); 〈assombração〉 FP (Q148); Ø (Q149); ‘amtleto FR (Q150); e «medalhinha〉 FP (Q153). Inf. 45: Ø (Q147); «sombração〉FP (Q148); ‘feitiço〉 FP (Q149); ‘amuleto〉 FA (Q150); e Ø (Q153). Inf. 46: «capeta〉FP (Q147); «espírito〉 FP (Q148); «macumba〉FP (Q149); ‘amuleto〉 FA (Q150); e «escapulário〉 FP (Q153). Inf. 47: «demônio〉 FP1 e «capeta`FP2 (Q147); ‘assombração〉 FP1 e «encosto` FP2 (Q148); «macumba〉 FP (Q149); ‘amuleto〉 FP (Q150); e «escapulário〉 FP (Q153). Inf. 48: 〈diabo〉 FP (Q147); Ø (Q148); ‘cruzes e velas〉FP (Q149); ‘amuleto〉FA (Q150); e 〈medalhinha〉(Q153). O Quadro 5 elenca essas lexias em ordem decrescente de instanciações em colunas onomasiológicas, excluídas as FRs. 


\begin{tabular}{|c|c|c|c|}
\hline Q147 & Q148 & Q149 & Q150 \\
\hline 4 «capeta〉 & 4 «(as)sombração» & 5 〈macumba & 6 <amuleto (da sorte) \\
\hline $3<$ diabo $>$ & 2 <espírito & 2 (feitiço» & Q153 \\
\hline 1 〈demônio» & 2 <fantasma & 1 〈cruzes e velas〉 & 4 〈medalha/medalhinha \\
\hline 1 〈lúcifer» & 1 <alma de outro mundo〉 & 1 <encosto〉 & 3 <escapulário» \\
\hline
\end{tabular}

Quadro 5: Vocabulário geral para Q147, Q148, Q149 e Q150

Em seu valor morfológico de face, «capeta〉 evidentemente é o resultado de 〈capa〉 + 〈-eta〉 (sufixo formador de diminutivo). Etimologicamente ${ }^{14}$, segundo Cunha (1989), «capeta», com registro que remota ao ano de 1899, designa 'diabo', 'traquinas', e tem sua motivação de aparecimento no costume de representar-se o diabo com uma pequena capa.

A lexia 〈diabo〉 etimologicamente denota 'gênio do mal, espírito das trevas, demônio, satanás, belzebu’ e era grafada 〈diaboo〉 ou 〈diabre〉 (séc. XIII). Descende do latim eclesiástico 〈dřăbǒlus〉, por sua vez derivado do grego 〈diábolos〉 (ou gr. eclesiástico 〈diabo〉), 'que desune, que calunia, que acusa’; de ‘ballein`, 'infundir ânimo, temor, respeito' (Cunha 1989).

Para Cunha (1989), ‘demônio〉 etimologicamente denota 'espírito maligno, gênio do mal' (séc. XIII), do latim «daemonium〉, procedente do grego 〈daimónion〉, de 〈daímōn〉. Já para Nascentes (1966), também do grego «daimónion`, a denotação é 'ente sobrenatural, gênio bom ou mau'. Para Machado (1977), 〈demônio〉 decorre do grego 〈daimónios`, 'que provém da divindade, enviado por um deus', 'divino, 'tà daimónia, o que provém dos deuses', 'que tem carácter divino, maravilhoso, extraordinário', pelo latim 〈daemǒň̌u〉, 'pequeno gênio'.

Quanto a 〈lúcifer〉, grafado 〈Locifer» no séc. XIII, advém do latim 〈luč̌fer», que deriva de 〈luč̌dus〉 a partir de 〈lucēre〉, 'luzir', de acordo com Cunha (1989). Para Nascentes (1966), a denotação é 'que traz um facho'. Já para Machado (1977), o étimo latino de 〈lúcifer〉 grafa-se 〈luč̌fĕr〉 e significa 'que traz lume,' 'que dá claridade' e figuradamente 'que produz luz (à verdade)'.

Documentado no séc. XX, ‘assombração〉 tem por base 〈sombra〉, 'espaço sem luz, ou escurecido pela interposição de um corpo opaco', grafado 〈soombra〉 no séc. XIV, ligado ao latim 〈ǔmbra〉 (Cunha 1989).

Com o significado 'parte imaterial do ser humano, alma', «espírito〉 grafava-se «spirito〉 ou «esperito〉 no séc. XIII e advém do latim 〈spīrǔtus〉 ou 〈spīrǔtūs〉, consoante Cunha (1989). Para Nascentes (1966), «espírito` advém do latim arcaico e (ainda hoje) popular «esprito` (o qual descende de «spiritu〉), usado por antigos químicos para designar produtos de destilação por sua primitiva volatilidade. Já para Machado (1977), 〈espírito〉 procede do latim 〈spirǐtu〉, 'sopro (de ar, de vento)', 'ar', 'ar aspirado', 'sopro, respiração, alento', 'ato da respiração', 'sopro (= vida)', 'suspiro' (poeticamente), 'aspiração' (na gramática), 'exalação, emanação, odor', 'sopro, inspiração' (na metafísica), 'suficiência, segurança, presunção, arrogância, orgulho' (figurativamente).

A lexia ‘fantasma〉 remonta ao séc. XVI e grafava-se ‘fantesia〉 no século XV, do latim «phantašà, por sua vez derivado do grego 〈phantasía`, 'imaginação, devaneio', segundo Cunha (1989).

14 Segue-se a partir daqui a tradição observada em textos lexicológicos de não se indicarem as páginas das obras consultadas, sendo a indicação dos verbetes uma informação suficiente para a localização exata das citações nos originais. 
Para Nascentes (1966), o percurso etimológico de ‘fantasia〉 é o mesmo, mas com o significado 'aparência, imagem, capricho, ilusão'. Já para Machado (1977), ‘fantasma〉 sai do grego ‘phántasma〉 via latim 〈phantasma〉, 'ser imaginário, espectro'.

No que tange à forma ‘alma〉, ela refere a 'essência imaterial do ser humano, espírito’ (séc. XIII), do latim 〈anǐma〉, segundo Cunha (1989). Nascentes (1966) hipotetiza *alima〉, um vulgarismo antigo do espanhol, procedente de 〈anima e precedente de 〈alma〉, forma sincopada do étimo hipotético. Já para Machado (1977), «alma〉 também decorre do latim 〈anǐma〉, mas significando 'sopro, ar,' 'alento' ou 'o princípio da vida'.

De 1706, «encosto〉 origina-se de «costa〉, 'espáduas' (séc. XIII), no plural, ou 'costela' (séc. XIII), ou 'litoral' (séc. XIV), do latim «cǒsta), 'costela, ilharga, lado, flanco', consoante Cunha (1989). Machado (1977) indica que «encosto é um derivado regressivo de «encostar», por sua vez saído de 〈costa〉, do latim homógrafo, significando 'costela' ou, figurativamente, 'lado, flanco'. Considerando-se ambas as fontes, não se verifica um nexo de conteúdo entre a perspectiva etimológica e a perspectiva sincrônica corrente com relação à área semântica da religião (ou da espiritualidade, até certa extensão). Por isso, diga-se que Houaiss e Villar (2009) (os quais datam «encosto〉 do ano 1561) apresentam uma acepção pejorativa corrente associada ao âmbito espiritual: 'espírito perturbado que se presume estar ao lado de alguém para prejudicar'.

A propósito de «macumba〉, Cunha (1989) informa que seu étimo é controverso, mas sua procedência é do quimbundo, denotando 'antigo instrumento musical de origem africana usado outrora nos terreiros', 'termo genérico para os cultos afro-brasileiros', 'quimbanda' ou 'despacho de rua (séc. XX). Para Nascentes (1966), o étimo de 〈macumba〉 é «ma’kũba〉 do quimbundo, 'cadeados, fechaduras', no âmbito de cerimônias de fechamento (grifo do autor) de corpos. Já para Machado (1977), «macumba〉 é 'feitiçaria'.

Do latim 〈factīcřus〉, 〈feitiço〉 como substantivo refere 'bruxaria, 'objeto a que se atribuem poderes sobrenaturais, amuleto’ ou 'encanto, fascinação’ (séc. XV), consoante Cunha (1989). Na ótica de Nascentes (1966), 〈feitiço〉 é uma substantivação do adjetivo homógrafo, significando 'artificioso', em função dos artifícios (grifo do autor) supersticiosos dos feiticeiros. Já para Machado (1977), 〈feitiço〉 advém do latim 〈factīcřu〉 e significa 'artificial, não natural, feito' ou, na gramática, 'palavra imitativa, formada por onomatopeia.

Quanto a «cruzes e velas`, por tratar-se, provavelmente, de um sintagma nominal meramente descritivo sem unidade lexical (característica de uma lexia), não parece pertinente abordá-la etimologicamente. Por seu turno, ‘amuleto (da sorte)〉 é, sem dúvidas, uma lexia, derivada do latim 〈amulētum〉, designando 'pequeno objeto que se usa ou guarda por se acreditar em seu poder mágico' (Cunha 1989). Para Machado (1977), trata-se do mesmo étimo, mas significando 'preservativo, talismã.

Sendo «medalhinha〉 apenas uma forma diminutiva de «medalha`, Cunha (1989) reporta que esta última remonta a 1780, denotando 'peça metálica, ordinariamente redonda, com emblema, efígie e inscrição' ou 'insígnia de ordem honorífica', do italiano «medaglia», a partir do latim hipotético * ${ }^{*} \operatorname{med}(\mathrm{i}) \overline{1}$ lia〉, originado de 〈mediālis〉, 'meio dinheiro', de 〈medǐus〉. Em sincronia corrente, Houaiss e Villar (2009) trazem uma acepção de cunho religioso resultante de uma analogia com a peça metálica (cuja descrição básica, para «medalha`, coincide com a de Cunha 1989): 'essa mesma peça, de formatos e materiais diversos, que apresenta figuras e motivos de devoção religiosa’. 
Por fim, 〈escapulário〉 é 'referente ao ombro' e deriva de 〈scapulario〉 (1570), de 〈escapullairo〉 (séc. XV), por sua vez plasmado do latim tardio «scapularium», na esteira de Cunha (1989), enquanto Nascentes (1966) menciona o latim tardio «scapularia`como base, forma nominativa/ acusativa neutra plural 〈scapularis〉 ou 〈scapulare〉. Machado (1977), por seu turno, considera «escapulário〉 gerado do latim * ${ }^{*}$ scapulariu〉 (tido pelo autor como um étimo hipotético), 'que cobre as espaduas. Pelo prisma sincrônico corrente, a acepção religiosa de «escapulário é 'objeto de devoção e símbolo de afiliação us[ado] nas ordens terceiras e em certas confrarias que consiste em dois pedaços de tecido bento unidos por cadarços que passam sobre os ombros e caem sobre o peito e as costas' (Houaiss e Villar 2009, grifo meu).

\section{Conclusões}

Em bulleted lists, seguem-se conclusões extraídas das observações e análises prévias concernentes às amostras de (1) Romero (2007) e de (2-8) Figueiredo Jr. (2019). Em cada linha das listas, o primeiro par de parênteses encerra o número da questão onomasiológica (dirigida aos informantes ${ }^{15}$ ), a qual equivale, retirado o aspecto interrogativo, à acepção empírica da lexia correspondente. Menciona-se a frequência relativa nos casos que contam com relativa melhor base quantitativa.

(1) Perspectiva diageracional ( $\mathrm{J}=$ entre os jovens; $\mathrm{V}=$ entre os velhos):

- 〈bentinho〉 (Q38), lexia regressiva (35\%-J, 90\%-V);

- 〈pátua〉(Q38), lexia progressiva (83,3-J, 50\%-V);

- 〈caborje〉 (Q39), lexia regressiva (0\%-J, 10\%-V); e

- 〈bataria〉(Q40), lexia regressiva (16\%-J, 40\%-V).

(2) Perspectiva geral, i.e., sem correlações com variáveis extralinguísticas:

- 〈diabo〉 e «capeta〉(Q147), lexias simetricamente rivais (33\% cada);

- 〈(as)sombração〉(Q148), lexia mais frequente (43\%);

- 〈macumba〉(Q149), norma lexical (71\%);

- 〈amuleto (da sorte)〉(Q150), norma lexical (100\%); e

- 〈medalha/medalhinha〉(Q153), norma lexical (66\%).

(3) Perspectiva diagenérica feminina:

- covariantes em variação simétrica generalizada (Q147, Q148, Q153);

- 〈macumba〉(Q149), norma lexical; e

- 〈amuleto (da sorte)〉(Q150), norma lexical.

(4) Perspectiva diagenérica masculina:

- covariantes em variação simétrica generalizada (Q147);

- 〈assombração〉(Q148), lexia prevalente;

- 〈macumba〉 (Q149), lexia prevalente; 
- 〈amuleto〉(Q150), norma lexical; e

- 〈medalha/medalhinha〉(Q153), norma lexical.

(5) Perspectiva mista: 〈assombração〉(Q148), lexia masculina.

(6) Perspectiva diageracional:

- 〈diabo〉(Q147), lexia estável;

- 〈capeta〉(Q147), lexia estável;

- 〈fantasma〉(Q148), lexia progressiva;

- 〈(as)sombração〉(Q148), lexia regressiva;

- 〈macumba〉 (Q149), lexia progressiva;

- 〈amuleto (da sorte)〉(Q150), lexia estável;

- 〈medalha/medalhinha〉(Q153), lexia regressiva; e

- 〈escapulário〉(Q153), lexia progressiva.

(7) Perspectiva diastrática:

- 〈diabo〉(Q147), lexia classista alta;

- 〈capeta〉(Q147), lexia classista baixa;

- 〈(as)sombração〉(Q148), lexia classista baixa;

- 〈fantasma〉(Q148), lexia imparcial;

- 〈macumba (Q149), lexia imparcial;

- 〈amuleto (da sorte)〉(Q150), lexia imparcial; e

- 〈medalha/medalhinha〉(Q153), lexia imparcial.

(8) Por fim, perspectiva diarreligiosa ${ }^{16}$ :

- 〈diabo〉(Q147), lexia católica e evangélica;

- 〈capeta〉(Q147), lexia católica e evangélica;

- 〈(as)sombração〉(Q148), lexia católica;

- 〈macumba (Q149), lexia católica e evangélica;

- 〈amuleto (da sorte)〉(Q150), lexia católica e evangélica; e

- 〈medalha/medalhinha〉(Q153), lexia católica.

\section{Considerações finais}

No momento, a Prefeitura de Itu e sua Secretaria de Cultura e do Patrimônio Histórico constroem as condições necessárias - conceituais, técnicas, financeiras e políticas - para lograr o tombamento de seu Centro Histórico junto ao Instituto do Patrimônio Histórico e Artístico Nacional (IPHAN).

16 Neste caso, todavia, considerando-se resultados assistemáticos, visto que a variável diarreligiosa não foi sistematicamente controlada. Quanto a esses mesmos resultados, a prevalência católica (em primeiro lugar) e evangélica (em segundo) não surpreende, uma vez que ambos os grupos religiosos juntos perfazem praticamente $90 \%$ da população ituana, se considerado o último censo demográfico, 2010 (SIDRA 2021), no qual 73\% da população declararam-se católicos; e 16\%, evangélicos. 
Com esse reconhecimento nacional inicial, o município elaborará sua candidatura junto ao IPHAN para tornar-se Patrimônio Mundial junto à Organização das Nações Unidas para a Educação, a Ciência e a Cultura (UNESCO). Para isso, a Diretoria de Patrimônio Histórico da localidade está em fase de angariar apoio técnico de instituições.

Nesse conjunto de ações, e em relação ao que mais de perto concerne a este artigo, um dos objetivos é tecnicamente documentar as características dialetais em geral - no presente recorte, lexicais orais da área semântica 'religião e crenças' em específico - da cidade, do que presumivelmente desdobrar-se-á a valorização de seu patrimônio linguístico, subsumido à categoria de paisagem cultural, uma das facetas mais importantes do patrimônio cultural ituano como um todo.

\section{Referências bibliográficas}

Amaral, A. (1920). O dialeto caipira. São Paulo: Anhembi.

Carvalho, M. R. (1987). Dicionário tupi (antigo)-português. Salvador: [s. n.]

Castilho, E. R. (2017). Itu, entre as ideias preservacionista e desenvolvimentista: da disputa patrimonial e turística à construção de uma imagem cultural ituana como cidade-museu. Rio de Janeiro: UNIRIO.

Coppes Jr., G. R. (2021). "Um problema histórico-geográfico”: emergências de um saber geográfico no Instituto Histórico e Geográfico de São Paulo. Uma geografia para e das bandeiras (1894-1954). Franca: UNESP.

[CNPA]: Comitê Nacional do Projeto ALiB. (2001). Atlas Linguístico do Brasil: questionários 2001. Londrina: Ed. UEL.

Cunha, A. G. (1989 [1982]). Dicionário etimológico Nova Fronteira da língua portuguesa. 2. ed. Rio de Janeiro: Nova Fronteira.

Ferreira, J. P. (org.) (1957). Enciclopédia dos municípios brasileiros. Vol. XXVIII. Lucas (DF): Oficinas do Serviço Gráfico do IBGE.

Figueiredo Jr., S. R. (2019). Atlas linguístico pluridimensional do português paulista: níveis semântico-lexical e fonético-fonológico do vernáculo da região do Médio Tietê. São Paulo: USP.

Figueiredo Jr., S. R.; Margotti, F. W.; Santiago-Almeida, M. M.; \& Nascimento, J. F. (2021). Metodologia geolinguística: agentes em geral e técnicas de inquérito semântico-lexical em específico. Cadernos de Estudos Linguísticos, 63, 1-16.

Francischinelli, F. L. C. (2019). Itu: a vila do açúcar (1780 a 1830). In M. S. D. Hadler, A. Paulilo, M. A. R. Ribeiro, \& J. F. Cerasoli (Orgs.). Anais do IX Seminário Nacional do CMU - Memória e histórias locais: esquecimento, diversidades culturais e identidades. Campinas: UNICAMP.

Garcia, R. R. (2015). A entoação do dialeto caipira do Médio Tietê: reconhecimento, características e formação. São Paulo: USP.

Holanda, S. B. (2000 [1945]) Monções. São Paulo: Brasiliense.

Houaiss, A.; Villar, M. S. (2009). Dicionário eletrônico Houaiss da língua portuguesa. Rio de Janeiro: Objetiva.

[IBGE]: Instituto Brasileiro de Geografia e Estatística (2021). Itu. <https://cidades.ibge.gov.br/brasil/sp/itu/ historico>

[IPHAN]: Instituto do Patrimônio Histórico e Artístico Nacional (2021). Lista dos Bens Tombados e Processos em Andamento (1938-2019). <http://portal.iphan.gov.br/pagina/detalhes/126> 
Machado, J. P. (1977 [1952]). Dicionário etimológico da língua portuguesa: com a mais antiga documentação escrita e conhecida de muitos dos vocábulos estudados. 3. ed. Lisboa: Horizonte.

Marins, P. C. G. (2016). Da porta do sertão ao porto: paisagem cultural e musealização. Comunicação oral (18 de maio de 2016). Itu (SP): Centro de Estudos do Museu Republicano "Convenção de Itu”.

Martins, M. E. (2012). A formação do Museu Republicano "Convenção de Itu” (1921-1946). São Paulo: USP.

Nascentes, A. (1966). Dicionário etimológico resumido. Rio de Janeiro: INL/MEC.

[PETI]: Prefeitura da Estância Turística de Itu (2021). Áreas de Proteção Ambiental (APAs). <https://itu.sp. gov.br/meio-ambiente/areas-de-protecao-ambiental-apas/>

Radtke, E.; \& Thun, H. (1996). Neue Wege der romanischen Geolinguistik: eine Bilanz. In E. Radtke, \& H. Thun (Orgs.) Akten des Symposiums zur empirischen Dialektologie (pp. 1-24). Kiel: Westensee-Verl.

Romero, R. M. L. (2007). Estudo semântico-lexical na região de Itu. São Paulo: USP.

[SP]: São Paulo (2016). Sistema Integrado de Gerenciamento de Recursos Hídricos do Estado de São Paulo. Governo do Estado de São Paulo. Recursos hídricos. <http://www.sigrh.sp.gov.br>

[SIDRA]: Sistema IBGE de Recuperação Automática (2021). Censo demográfico [2010]. «sidra.ibge.gov.br〉

Thun, H. (2005). A Dialetologia Pluridimensional no Rio da Prata. In A. M. S. Zilles (Org.). Estudos de variação linguística no Brasil e no Cone Sul (pp. 63-92). Porto Alegre: Ed. UFRGS.

Thun, H. (Dir.) (2000). Atlas lingüístico diatópico y diastrático del Uruguay. Kiel: Westensee-Verl.

Toscano, J. W.; \& Toscano, O. H. S. (1977). Análise urbana: considerações sobre a estrutura do diagnóstico geral da cidade de Itu. In J. W. Toscano; O. H. S. Toscano (Orgs.). Diagnóstico geral da cidade de Itu para a implantação de um programa de ação cultural - relatório final. São Paulo: [mimeografado].

Ximenes, D. S. S. (2018). Projeto urbano sustentável para a cidade de Itu: ligação centro histórico e o novo centro. São Paulo: USP. 
